\title{
Anti-Edema Effect of Epigallocatechin against Acute Spinal Cord Injury in Rats and its Correlation with the P38MAPK/NF- $\kappa$ b Signaling Pathway
}

\section{Lin Tao and Yue Zhu*}

Department of Orthopaedics, The First Hospital of China Medical University, Heping District, Shenyang, Liaoning, PR China

\begin{abstract}
Study Design: This study investigated the outcome of epigallocatechin (EGCG) against edema after spinal cord injury $(\mathrm{SCl})$.

Objective: To perform the evidence correlation of EGCG with p38MAPKINF-KB\AQP4 signaling pathway, also explore the effect of EGCG on edema after SCI, and clarify the possible mechanism of the EGCG reducing the edema
\end{abstract} after SCl.

Summary of background data: Although some studies show that EGCG have a protective effect on nerve cells, there are few documents covering the relation between EGCG and SCI. On the basis of confirming significant inhibition of EGCG against edema after $\mathrm{SCl}$, our research group intended to take the lead in further demonstrating the mechanism of anti-edema of EGCG against SCI.

Methods: 160 rats were randomly divided into sham - surgery, SCI, EGCG and specific p38MAPK inhibitor SB203580 treatment groups, every group contained 40 rats. Acute SCI models were established in rats by vascular clip method. We used sensitive ELISA to examine the level of TNF- $\alpha$ and IL-1 $\beta$, Western blot to examine the expression of $\mathrm{p} 38 \mathrm{MAPK} / \mathrm{NF}-\mathrm{kB} / \mathrm{AQP} 4$ signaling pathway related protein, the change of water content in spinal cord to evaluate the effect of EGCG against edema after SCI therapy.

Results: Both EGCG and SB203580 groups could significantly reduce the releasing of TNF- $\alpha$ and IL-1ß (P<0.05), while EGCG had a better effect $(P<0.05)$, thus EGCG could significantly inhibit the phosphorylation status of $p 38 M A P K$ reduce the expression of NF-KB p65 and AQP4 $(\mathrm{P}<0.05)$, and decrease the water content after $\mathrm{SCl}(\mathrm{P}<0.05)$, similar to SB203580.

Conclusion: The experimental findings indicate that EGCG can protect secondary SCI by potential mechanism of regulating p38MAPKINF -KB\AQP4 signaling pathway and thus reduce edema after $\mathrm{SCl}$.

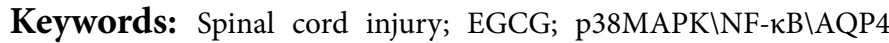
signaling pathway; Anti-edema

\section{Introduction}

Spinal cord injury (SCI) is a serious health problem with high care costs and involves primary and secondary mechanisms of injury. SCI destroys the local nerve tissues at the injured site by mechanical trauma. The secondary injury can destroy neighbouring nerve tissue that is not involved in the primary injury [1]. The mechanism associated with secondary injury include edema, altered blood flow and changes in microvascular permeability [2], the secondary injury is the main reason for functional disturbance of neural system. It is the key to curing SCI, the specific link that is susceptible to therapy. This is especially important since drug treatment is an essential part of SCI treatment and recovery and can affect the prognosis. Up till now, the only drug effective for the treatment of acute spinal cord injury is methylprednisolone [3], even this drug is receiving scepticism from orthopaedics specialists due to its narrow application window and various complications [4]. Therefore, to find a safe and effective drug which can be long-term used has been a hot and difficult problem for many orthopaedic experts.

Epigallocatechin (EGCG) is a primary polyphenol content of green tea, and it is a kind of natural antioxidant [5]. It can transfer through the blood-brain-barrier (BBB), protect nerve cells from injuries caused by free radical, and potentially treat neural damages $[6,7]$. Khalatbary et al. first demonstrated that EGCG could improve function recovery after SCI and protect injured tissues from further damages [8]. Our research group first defined that EGCG had an obvious effect against edema after SCI and further succeeded in curing secondary SCI, but the mechanism is still unknown [9].

With further understanding of various signaling pathways, advances have been made in blocking certain signaling pathways for the treatment of secondary damage following SCI [10,11]. Aquaporin$4(\mathrm{AQP} 4)$ is the most abundant water channel protein in the central neural system and plays a major role in regulating water balance in spinal cord $[12,13]$. Mitogen-activated protein kinase (MAPK) is the most important signaling system in mammalian cells and is involved in the regulation of cell edema, proliferation, development, differentiation and inflammation $[14,15]$. As is recently reported, p38MAPK participated in the expression of AQP4 of astrocyte glial cells in cerebral cortex of rats, alleviating cell edema after cerebral ischemia [16]. Therefore, on the basis of the previous researches, our study intended to observe whether EGCG could block the p38MAPK/NF- $\kappa$ B signaling pathway to regulate the expression of AQP4 after SCI by p38MAPK/NF- $\kappa$ B and thus reduce cell edema.

In addition, the previous research used EGCG at 25,50 and $100 \mathrm{mg} /$ $\mathrm{kg}$ dose for the treatment of SCI, and $100 \mathrm{mg} / \mathrm{kg}$ dose group had better efficacy than 25 and $50 \mathrm{mg} / \mathrm{kg}$ dose groups [17]. Our study showed that the EGCG $(100 \mathrm{mg} / \mathrm{kg})$ treatment had better therapeutic effects

*Corresponding author: Yue Zhu, Department of Orthopaedics, The First Hospital of China Medical University, No. 155 Nanjing Bei Street, Heping Districs Shenyang 110001. Liaoning Province, PR China, Tel: +86-24-83283380; Fax: +862483282772; E-mail: zhuyuedr@163.com

Received November 04, 2013; Accepted December 20, 2013; Published December 23, 2013

Citation: Tao L, Zhu Y (2013) Anti-Edema Effect of Epigallocatechin against Acute Spinal Cord Injury in Rats and its Correlation with the P38MAPK/NF-Kb Signaling Pathway. J Spine S4: 006. doi:10.4172/2165-7939.S4-006

Copyright: (c) 2013 Tao L, et al. This is an open-access article distributed unde the terms of the Creative Commons Attribution License, which permits unrestricted use, distribution, and reproduction in any medium, provided the original author and source are credited. 
following SCI, especially at $24 \mathrm{~h}$ [9]. In this study, we chose $100 \mathrm{mg} / \mathrm{kg}$ does of EGCG for the treatment of SCI at $24 \mathrm{~h}$ after injury. The specific p38MAPK inhibitor, SB203580 [18], was also used as positive control drug to investigate correlation between EGCG and the p38MAPK/NF- $\kappa$ $\mathrm{B} / \mathrm{AQP}-4$ signaling pathway, so as to elucidate the potential protective mechanism of EGCG against edema after secondary SCI.

\section{Materials and Methods}

\section{Animals}

The adult male Sprague - Dawley (SD) rats $(210-230 \mathrm{~g})$ were purchased from the Experimental Animals Center of China Medical University. All animal experiments were conducted in accordance with the National Institute of Health Guide for the Care and Use of Laboratory Animals. All possible efforts were made to minimize the suffering of the experimental animals.

\section{Spinal cord injury model}

Rats were anesthetized with chloral hydrate $(300 \mathrm{mg} / \mathrm{kg}$ body weight). The skin and muscle overlying the spinal column were incised and a laminectomy was performed at T12 level vertebra, leaving the dura intact. The spinal cord was compressed with a vascular clip (occlusion pressure, $30 \mathrm{~g}$ ) for exactly $1 \mathrm{~min}$. Only injured rats with a Basso, Beattie and Bresnahan (BBB) locomotor rating of $\leq 1$ (corresponding to a slight movement of 1 or 2 joints) were included in the study. During recovery from anesthesia, the rats were placed on a warm heating pad and covered with a warm towel. Food and water were provided to the rats. The urinary bladders were pressed three times a day [9].

\section{Experimental groups}

Four groups with randomly divided Sprague-Dawley rats: Shamsurgery group, which underwent laminectomy alone, without dural compression; SCI group, which underwent laminectomy followed by SCI and received saline i.p. immediately after injury; SCI + EGCG group Hangzhou Gosun Biotechnologies Co., Ltd., China), which underwent laminectomy followed by SCI and received a $100 \mathrm{mg} / \mathrm{kg}$ dose of EGCG i.p. immediately after SCI; SCI + SB203580 (Sigma, USA) group, which underwent laminectomy followed by SCI and received a $10 \mathrm{mg} / \mathrm{kg}$ dose of SB203580 (5 g/ml fulled dissolved into dimethyl sulfoxide) i.p. immediately after SCI. Each group was given the same amount of saline.

\section{ELISA test}

The samples were collected from the damaged spinal cord tissue at $24 \mathrm{~h}$ after injury and homogenized. The mixed was then centrifuged at $10000 \mathrm{~g}$ for $30 \mathrm{~min}$ at $4^{\circ} \mathrm{C}$. The supernatant was applied to measured TNF- $\alpha$ and IL- $1 \beta$ by enzyme - linked immunosorbent assay (ELISA). The specific steps according to ELISA kits (Biosource International Inc, Camarillo, CA, USA).

\section{Western blot}

The Spinal cord samples were $1 \mathrm{~cm}$ long and were homogenized in RIPA buffer. The homogenate was centrifuged for $15 \mathrm{~min}$ at $4^{\circ} \mathrm{C}$ at $10000 \mathrm{~g}$ to obtain membrane fractions for AQP4, total-p38MAPK, phospho - p38MAPK and NF- $\mathrm{kB}$ p65. Proteins were separated in $12 \%$ SDS - polyacrylamide gel, and the electrophoretically transferred onto PVDF membranes. Block the blot with 5\% skimmed for $2 \mathrm{~h}$. Then the membranes were incubated with primary polyclonal antibody against membrane proteins. Rabbit anti - rat AQP4 antibody (H - 80) was purchased from Santa Cruz Biotechnology, Inc (Delaware Ave Santa Cruz, USA), Rabbit anti - rat total - 38MAPK antibody(\#9212), rabbit anti-rat phospho-p38MAPK antibody (\#9215) and rabbit anti-rat NF- $\kappa B$ p65 antibody (\#8242) were purchased from Cell Signaling Technology (Danvers, MA, USA), overnight at 40C. After washing, the membranes were incubated with secondary antibody for $2 \mathrm{~h}$ at $4^{\circ} \mathrm{C}$ temperature, anti-rabbit secondary antibody (\#7074) was purchased from Cell Signaling Technology (Danvers, MA, USA), rabbit anti-rat $\beta$-Actin antibody $(\mathrm{R}$ - 22) was purchased from Santa Cruz Biotechnology, Inc (Delaware Ave Santa Cruz, USA).

Western blotting was performed with an ECL western blotting detection Kit (UVP Inc Upland CA, USA). The optical density was quantified using Image J Software (NIH, Bethesda, MD, USA). The value of the protein was normalized to the corresponding $\beta$-actin band. All experiments were repeated at least two times to ensure reproducibility of the results.

\section{Value of spinal cord water content}

Spinal cord edema was evaluated by determining spinal cord water content. The cords were removed at $24 \mathrm{~h}$ after surgery in every group. The spinal cords were $1 \mathrm{~cm}$ long segment centered at the injury epicenter. After determination of the wet weight, the injured spinal cords were dried for $48 \mathrm{~h}$ at $80^{\circ} \mathrm{C}$ for determination of the dry weight. Water content in spinal cord tissue was calculated as (wet weight - dry weight)/wet weight ${ }^{\star} 100 \%$.

\section{Statistical analysis}

Statistical analysis among groups was performed using one-way or two-way analysis of variance (ANOVA) with Student-Newman-Keuls multiple comparison test. Data were expressed as the mean \pm SEM. The level of significance was set at $\mathrm{p}<0.05$.

\section{Results}

\section{Regulatory effect of inflammatory factors by EGCG}

The expression of TNF- $\alpha$ and IL- $1 \beta$ was examined by ELISA Test to discuss the regulatory effect of EGCG on edema after SCI, SB203580 was used as a positive contrast drug to explore the relationship of EGCG and P38MAPK signaling pathway.

Reduction of TNF- $\alpha$ level by EGCG treatment: TNF- $\alpha$ content significantly increased at $24 \mathrm{~h}$ in the SCI group compared with the shamsurgery group $(\mathrm{P}<0.05)$, while significantly decreased in the EGCG and SB203580 treatment groups compared with the SCI group $(\mathrm{P}<0.05)$, and the amount in the EGCG group is more obvious than the SB203580 group $(\mathrm{P}<0.05)$ (Figure 1$)$.

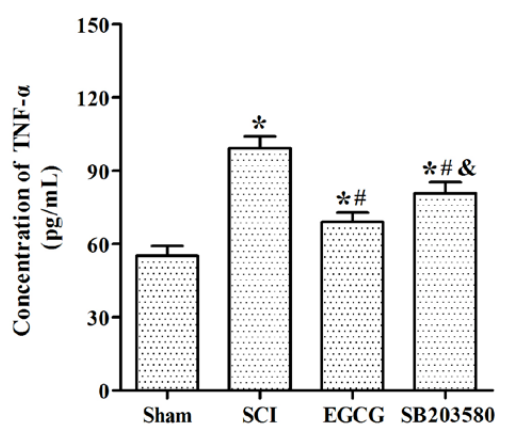

Figure 1: EGCG reduction of TNF- $\alpha$ level in the spinal cord of SCI rats. TNF-a level in the spinal cord of SCI rats with and without EGCG or SB203580 treatment at $24 \mathrm{~h}$. Data are represented as means \pm SD for four replicate tests. ${ }^{*} p<0.05$ compared with the sham-surgery group; $\# p<0.05$ compared with the SCl group; \& $p<0.05$ compared with the SCI +EGCG group. 
Reduction of IL-1 $\beta$ level by EGCG treatment: IL- $1 \beta$ content significantly increased at $24 \mathrm{~h}$ in the SCI group compared with the sham-surgery group $(\mathrm{P}<0.05)$, while significantly decreased in the EGCG and SB203580 treatment groups compared with the SCI group $(\mathrm{P}<0.05)$, and the amount of IL- $1 \beta$ is lower in the EGCG group compared with the SB203580 group $(\mathrm{P}<0.05)$, similar to the changes of TNF-a (Figure 2).

\section{Inhibition of p38MAPK/NF-kB/AQP4 by EGCG}

The results above showed that EGCG could inhibit the expression of TNF- $\alpha$ and IL- $1 \beta$ significantly, and the EGCG group had similar effect as the SB203580 group, suggesting the mechanism of EGCG might have a possible relation with p38MAPK pathway. On the basis of this, to further explore the effect of EGCG, we observed the expression of total-p38MAPK, phospho-p38MAPK, NF- $\kappa$ B p65 and AQP4 just at $24 \mathrm{~h}$ after SCI treated by EGCG, discussed that EGCG treated edema after SCI via $\mathrm{p} 38 \mathrm{MAPK} \backslash \mathrm{NF}-\kappa \mathrm{B} \backslash \mathrm{AQP} 4$ signaling pathway.

Inhibition of phospho-p38MAPK expression by EGCG: The expression of phospho-p38 MAPK protein was very low in the sham-

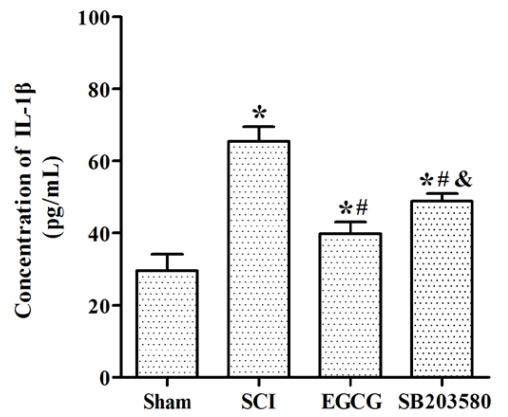

Figure 2: $E G C G$ reduction of $\mathrm{IL}-1 \beta$ level in the spinal cord of $\mathrm{SCl}$ rats. IL$1 \beta$ level in the spinal cord of SCI rats with and without EGCG or SB203580 treatment at $24 \mathrm{~h}$. Data are represented as means \pm SD for four replicate tests. ${ }^{*} \mathrm{p}<0.05$ compared with the sham-surgery group; $\# p<0.05$ compared with the $\mathrm{SCl}$ group; \& $\mathrm{p}<0.05$ compared with the $\mathrm{SCl}+\mathrm{EGCG}$ group.

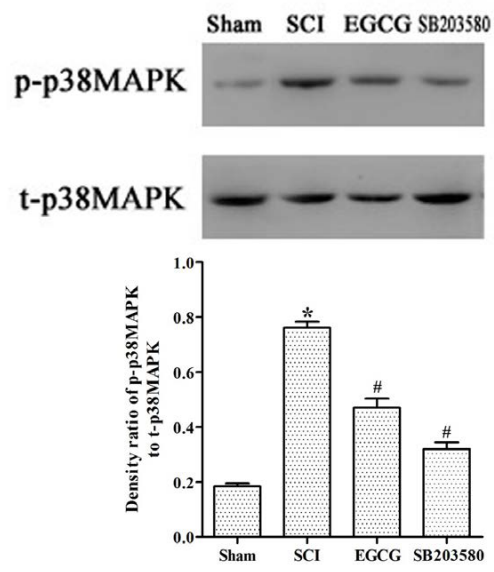

Figure 3: EGCG reduction of phospho-p38MAPK contents in the spinal cord of $\mathrm{SCl}$ rats. phospho-p38MAPK contents in the spinal cord of $\mathrm{SCl}$ rats with and without EGCG or SB203580 treatment at 24h. (A) Result of Western blotting. (B) The bar graph showing the quantitative analysis of the protein levels of phospho-p38MAPK in the injured spinal cord in 4 groups. Data are represented as means \pm SD for four replicate tests. ${ }^{*} p<0.05$ compared with the sham-surgery group; ${ }^{*} p<0.05$ compared with the $\mathrm{SCl}$ group.

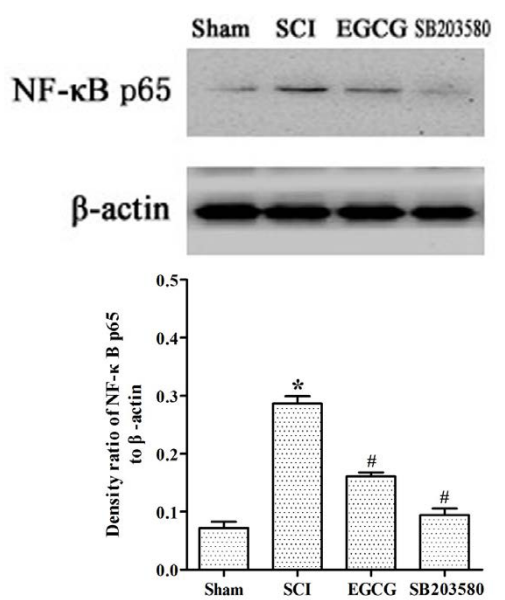

Figure 4: EGCG reduction of NF-kB p65 contents in the spinal cord of SCI rats NF-KB p65 contents in the spinal cord of SCl rats with and without EGCG or SB203580 treatment at $24 \mathrm{~h}$. (A) Result of Western blotting. (B) The bar graph showing the quantitative analysis of the protein levels of NF-KB p65 contents in the injured spinal cord in 4 groups. Data are represented as means \pm SD for four replicate tests. ${ }^{*} p<0.05$ compared with the sham-surgery group; ${ }^{*} p<0.05$ compared with the $\mathrm{SCl}$ group.

surgery group, while it increased significantly in the SCI group $(\mathrm{p}<0.05)$ In the EGCG and SB203580 treatment groups, the down regulation of phospho-p38MAPK is also obvious $(\mathrm{p}<0.05)$. Expression of totalp38MAPK almost had no change in the groups (Figure 3 ).

Downregulation of NF-kB p65 expression by EGCG: As results showed, small amount of NF-kB p65 expressed in the sham-surgery group, while significantly increased in the SCI group, but the EGCG and SB203580 could reduce the expression of NF- $\kappa \mathrm{B}(\mathrm{P}<0.05)$ (Figure $4)$.

Downregulation of AQP4 expression by EGCG: Our previous results showed AQP4 positive cells were strongly expressed in gray matter, around capillaries and in radial astrocytes with immunohistochemistry. There was significantly up-regulation the number of AQP4 positive cells in the SCI group compared with in the sham-surgery group at 24 $\mathrm{h}$ after injury, but the EGCG significantly down-regulation the number of AQP4 positive cells was at $24 \mathrm{~h}$ after injury compared with that of the SCI group [9], to further study the effect of EGCG on AQP4 protein expression, we used Western blot to detect the protein level of AQP4. The results showed that the protein was expressed at low level in the spinal cords of the sham-surgery group, however, the level of AQP4 significantly increased in the SCI group compared with AQP4 level of the sham group $(\mathrm{P}<0.05)$. Furthermore, the protein expression of AQP4 in the EGCG and SB203580 treat groups were significantly lower than that of the SCI group $(\mathrm{P}<0.05)$ (Figure 5).

\section{Effect of EGCG on spinal cord water content}

Results from the present study proved that EGCG against SCI therapy regulated AQP4 expression through p38MAPK/NF- $\kappa B$ pathway, to further confirm EGCG therapy effect, we used water content after SCI to reflect the seriousness of edema.

The result of spinal cord water content was shown in Figure 6. The spinal cord water content after injury was significantly increased in the SCI group compared with the sham-surgery group at $24 \mathrm{~h}$ after injury. In addition, both EGCG and SB203580 reduced spinal cord water content in the SCI rats after injury, with EGCG effects being stronger. 


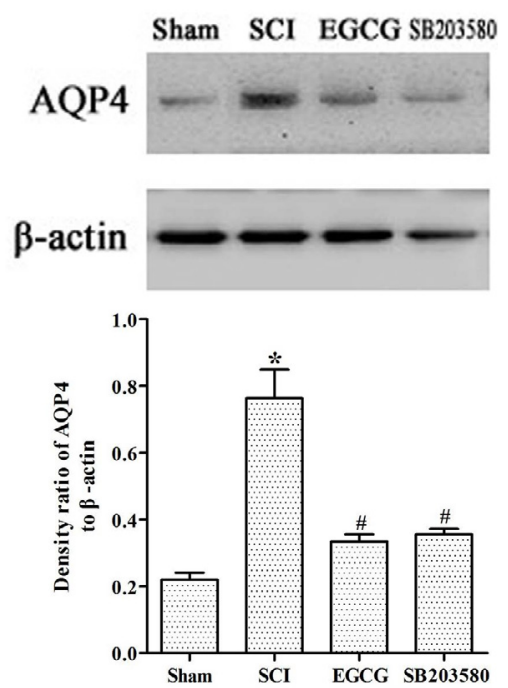

Figure 5: EGCG reduction of AQP4 contents in the spinal cord of $\mathrm{SCl}$ rats AQP4 contents in the spinal cord of SCl rats with and without EGCG or SB203580 treatment at $24 \mathrm{~h}$. (A) Result of Western blotting. (B) The bar graph showing the quantitative analysis of the protein levels of AQP4 contents in the injured spinal cord in 4 groups. Data are represented as means \pm SD for four replicate tests. ${ }^{*} p<0.05$ compared with the sham-surgery group; ${ }^{*} p<0.05$ compared with the $\mathrm{SCl}$ group.

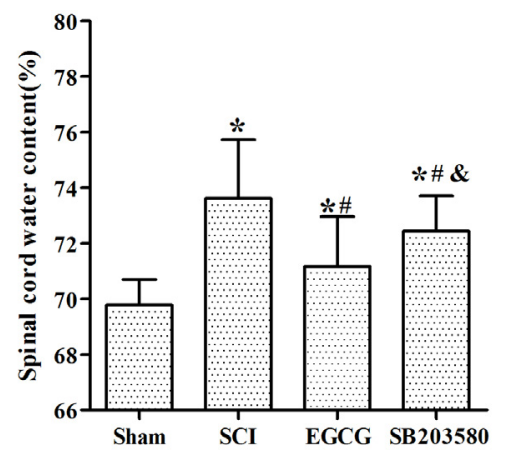

Figure 6: EGCG reduction of the spinal cord water content in the spinal cord of $\mathrm{SCl}$ rats. The spinal cord water content in the spinal cord of SCl rats with and without EGCG or SB203580 treatment at $24 \mathrm{~h}$. Data are represented as means \pm SD for four replicate tests. ${ }^{*} p<0.05$ compared with the sham-surgery group; ${ }^{*} p<0.05$ compared with the $\mathrm{SCl}$ group; \& $\mathrm{p}<0.05$ compared with the SCl + EGCG group.

\section{Discussion}

This research is focused on how to relieve edema after secondary SCI and its potential mechanism. Secondary SCI is a complex of pathological and biological process which many factors are involved $[19,20]$. Many clinical and experimental studies have proved that TNF- $\alpha$ plays a vital role in immunological regulation and inflammatory process of SCI [21]. TNF- $\alpha$ can promote the expression of microvascular endothelial cell adhesion moleculars, induce the production of neutrophilic granulocyte and mononuclear cell chemokines, lead leukocytes aggregation and adhesion, as well as migrate from capillaries to lesion tissue to exacerbate inflammatory reactions. In addition, it can active glial cells, cause glial hyperplasia and scar formation, destroy blood - spinal barrier, induce the release of arachidonic acid metabolic product. It is also said that TNF- $\alpha$ is related to lipidhydroperoxide and oxygen free racidal production $[22,23]$. IL-1 $\beta$ can also activate a series of adhesion molecules and expressions of inflammatory factors which promote the damage of injury sites $[24,25]$. It has been shown that TNF- $\alpha$ and IL- $1 \beta$ play a crucial role in secondary SCI and that EGCG treats edema after SCI, but the association between TNF- $\alpha$, IL$1 \beta$ and EGCG is not mentioned. We adopted ELISA to examine the level of TNF- $\alpha$ and IL- $1 \beta$, and found that the expression of TNF- $\alpha$ and IL- $1 \beta$ significantly increased at $24 \mathrm{~h}$ edema after secondary SCI, while EGCG and SB203580 could both significantly reduce TNF- $\alpha$ and IL-1 $\beta$ expression, and EGCG's effect was more obvious, indicating that EGCG against edema after secondary SCI therapy had a possible relation with p38MAPK pathway.

MAPK super family is Serine/Threonine protein kinase which spreads widely through cytoplasm. It transmits extracellular stimulating signals to nucleus, and evokes important signal system in cell biochemistry reactions. Previous report had shown four MAPK subfamilies in eukaryocyte: extracellular signal - regulated kinase (ERK)1/2, p38MAPK, c-JUN N-terminal kinases JNK and ERK5 [26]. ST Denis [27] reported that P38MAPK signaling pathway was closely associated with inflammatory reactions and ischemia further study indicated that inhibiting P38MAPK phosphorylation could reduce or even block production of TNF- $\alpha$. This suggests that TNF- $\alpha$ is associated with the phosphorylation status of p38MAPK; Another study reported that p38MAPK translocates into nucleus, phosphorylates transcription factors such as NF- $\kappa B$ or AP1. Nuclear factor- kappa B (NF-kB) is a dimer composed of p65 and p50. It is distributed in almost all the eukaryotic cells and plays a very important role in the process of ischemia, inflammatory reaction, immune reactivity, cell growth and apoptosis as a regulational transcript factor [28], however, only p65 is expressed widely and has strongest activity. The activated NF- $\mathrm{KB}$ can participate alone or synergy with other transcription factors in many reactions, like the induction and expression of inflammatory cell factors, such as TNF- $\alpha$ IL- $1 \beta$, IL- 6 , IL- 8 , ICAM- 1 . These induced genes products can participate in some biological reactions under mechanical trauma condition $[29,30]$. We used Western blot to examine the expression of total - p38MAPK, phospho - p38MAPK and NF- $\kappa B$ p65, as results had shown that phospho-p38MAPK was rarely activated in the sham-surgery group while in the SCI group phospho - p38MAPK expression was significantly increased, greatly differentiated from the sham - surgery group. However, in the EGCG and SB203580 groups, the expression of phospho - p38MAPK was significantly inhibited. At the same time, we found that NF- $\kappa B$ p 65 expression in the SCI group was sharply increased, indicating that NF- $\mathrm{kB}$ p 65 was activated after secondary SCI. Moreover, the expression of NF- $\kappa B$ p65 was proportioned with phospho - p38MAPK implicating that phospho $\mathrm{p} 38 \mathrm{MAPK}$ is the upstream regulator of NF- $\kappa \mathrm{B}$ p65. In contrast, EGCG and SB203580 groups had the same effect of reducing the NF- $\kappa$ B p65 expression. The study shows that in edema after SCI, phosphorylated p38MAPK translocates into the nucleus, phosphorylate nucleus factors NF- $\kappa B$ p 65 to take biological effects. In conclusion, EGCG against edema after secondary SCI therapy is related to p38MAPK/NF $-\kappa B$ signaling pathway.

AQPs is a kind of cell membrane transport protein which has high selectivity for $\mathrm{H} 2 \mathrm{O}$, and AQP4 mostly exists in nerve tissues. Nesic and his colleagues were the first to prove that edema after SCI was highly relevant to AQP4 [31]. Thrane also proved that AQP4 - /- rats, the cell edema of astrocytes caused by hypotonic could be relieved [32]. Chikako Nito found that block p38MAPK phosphorylation, the expression of AQP4 in astrocytes after ischemia could be decreased to some extent [33]. Above all, we speculate that the p38MAPK/NF$\kappa \mathrm{B}$ pathway could regulate the expression of AQP4 protein to relieve 
the cell edema. On the basis of our previous immunohistochemical results, we used Western blot to examine AQP4 protein [9]. From the Western blot results, there was a significant increase in AQP4 in the SCI group, while a decline in the EGCG and SB203580 groups. This indicate that the activation of $\mathrm{p} 38 \mathrm{MAPK} / \mathrm{NF}-\mathrm{\kappa B} / \mathrm{AQP} 4$ signaling pathway is involved in the edema after secondary SCI, and EGCG treatment can inhibit the activation of the $\mathrm{p} 38 \mathrm{MAPK} / \mathrm{NF}-\mathrm{k} \mathrm{B} / \mathrm{AQP} 4$ pathway.

Finally, to further confirm EGCG therapy effect, we used water content of spinal cord after SCI to reflect the seriousness of edema. As results showed, compared to the sham-surgery group, water content in the SCI group was significantly increased, indicating that spinal marrow had a serious edema, however, water content in EGCG and SB203580 groups were significantly declined.

In conclusion, the present study shows that EGCG regulates AQP4 expression to reduce cell edema after SCI through inhibiting the phosphorylation status of $\mathrm{p} 38 \mathrm{MAPK}$, reducing the expression of NF$\mathrm{\kappa B}$ p65. Aiming at curing SCIthe above experimental findings provide basic theory for EGCG in clinical application, meanwhile we find that EGCG are better to manage the edema after SCI than SB203580, so further studies are required to determine the detailed regulation mechanisms of EGCG.

\section{References}

1. Carlson GD, Gorden CD, Oliff HS, Pillai JJ, LaManna JC (2003) Sustained spina cord compression: part I: time-dependent effect on long-term pathophysiology. J Bone Joint Surg Am 85-85A: 86-94.

2. Rowland JW, Hawryluk GW, Kwon B, Fehlings MG (2008) Current status of acute spinal cord injury pathophysiology and emerging therapies: promise on the horizon. Neurosurg Focus 25: E2.

3. Oshio K, Binder DK, Yang B, Schecter S, Verkman AS, et al. (2004) Expression of aquaporin water channels in mouse spinal cord. Neuroscience 127: 685-693.

4. Ito Y, Sugimoto Y, Tomioka M, Kai N, Tanaka M (2009) Does high dose methylprednisolone sodium succinate really improve neurological status in patient with acute cervical cord injury?: a prospective study about neurological recovery and early complications. Spine (Phila Pa 1976) 34: 2121-2124.

5. Büttemeyer R, Philipp AW, Schlenzka L, Mall JW, Beissenhirtz M, et al. (2003) Epigallocatechin gallate can significantly decrease free oxygen radicals in the reperfusion injury in vivo. Transplant Proc 35: 3116-3120.

6. Itoh T, Imano M, Nishida S, Tsubaki M, Mizuguchi N, et al. (2012) (-)-Epigallocatechin-3-gallate increases the number of neural stem cells around the damaged area after rat traumatic brain injury. J Neural Transm 119: $877-$ 890

7. Wei IH, Tu HC, Huang CC, Tsai MH, Tseng CY, et al. (2011) (-)-Epigallocatechin gallate attenuates NADPH-d/nNOS expression in motor neurons of rats following peripheral nerve injury. BMC Neurosci 12: 52.

8. Khalatbary AR, Tiraihi T, Boroujeni MB, Ahmadvand H, Tavafi M, et al. (2010) Effects of epigallocatechin gallate on tissue protection and functional recovery after contusive spinal cord injury in rats. Brain Res 1306: 168-175.

9. Ge R, Zhu Y, Diao Y, Tao L, Yuan W, et al. (2013) Anti-edema effect of epigallocatechin gallate on spinal cord injury in rats. Brain Res 1527: 40-46.

10. Park KK, Liu K, Hu Y, Smith PD, Wang C, et al. (2008) Promoting axon regeneration in the adult CNS by modulation of the PTEN/mTOR pathway. Science 322: 963-966.

11. Song Y, Zeng Z, Jin C, Zhang J, Ding B, et al. (2013) Protective effect of ginkgolide $B$ against acute spinal cord injury in rats and its correlation with the Jak/STAT signaling pathway. Neurochem Res 38: 610-619.

12. Yoneda K, Yamamoto N, Asai K, Sobue K, Fujita Y, et al. (2001) Regulation of aquaporin-4 expression in astrocytes. Brain Res Mol Brain Res 89: 94-102.

13. Manley GT, Binder DK, Papadopoulos MC, Verkman AS (2004) New insights into water transport and edema in the central nervous system from phenotype analysis of aquaporin-4 null mice. Neuroscience 129: 983-991.

14. Yang M, Xiao C, Wu Q, Niu M, Yao Q, et al. (2010) Anti-inflammatory effect of Sanshuibaihu decoction may be associated with nuclear factor-kappa B and p38 MAPK alpha in collagen-induced arthritis in rat. J Ethnopharmacol 127 264-273.

15. Kook SH, Jeon YM, Lim SS, Jang MJ, Cho ES, et al. (2013) Fibroblast growth factor-4 enhances proliferation of mouse embryonic stem cells via activation of c-Jun signaling. PLoS One 8: e71641.

16. Tang Z, Sun X, Huo G, Xie Y, Shi Q, et al. (2013) Protective effects of erythropoietin on astrocytic swelling after oxygen-glucose deprivation and reoxygenation: mediation through AQP4 expression and MAPK pathway. Neuropharmacology 67: 8-15.

17. Deng F, Li R, Yang Y, Zhou D, Wang Q, et al. (2011) Neuroprotective effect of epigallocatechin-3-gallate on hemisection-induced spinal cord injury in rats. Neural Regen Res 6: 405-411.

18. Wang XJ, Kong KM, Qi WL, Ye WL, Song PS (2005) Interleukin-1 beta induction of neuron apoptosis depends on p38 mitogen-activated protein kinase activity after spinal cord injury. Acta Pharmacol Sin 26: 934-942.

19. Yoshino O, Matsuno H, Nakamura H, Yudoh K, Abe Y, et al. (2004) The role of Fas-mediated apoptosis after traumatic spinal cord injury. Spine (Phila Pa 1976) 29: 1394-1404

20. Citron BA, Arnold PM, Haynes NG, Ameenuddin S, Farooque M, et al. (2008) Neuroprotective effects of caspase-3 inhibition on functional recovery and tissue sparing after acute spinal cord injury. Spine (Phila Pa 1976) 33: 22692277

21. Chen KB, Uchida K, Nakajima H, Yayama T, Hirai T, et al. (2011) Tumo necrosis factor-Ît antagonist reduces apoptosis of neurons and oligodendroglia in rat spinal cord injury. Spine (Phila Pa 1976) 36: 1350-1358.

22. Bethea JR, Dietrich WD (2002) Targeting the host inflammatory response in traumatic spinal cord injury. Curr Opin Neurol 15: 355-360.

23. Moore SA, Oglesbee MJ (2012) Involvement of the choroid plexus in the inflammatory response after acute spinal cord injury in dogs: an immunohistochemical study. Vet Immunol Immunopathol 148: 348-352.

24. Yang L, Blumbergs PC, Jones NR, Manavis J, Sarvestani GT, et al. (2004) Ghabriel MN. Early expression and cellular localization of proinflammatory cytokines interleukin-1beta, interleukin-6, and tumor necrosis factor-alpha in human traumatic spinal cord injury. Spine (Phila Pa 1976) 29: 966-971.

25. Cuzzocrea S, Deigner HP, Genovese T, Mazzon E, Esposito E, et al. (2009) Inhibition of ceramide biosynthesis ameliorates pathological consequences of spinal cord injury. Shock 31: 634-644.

26. Kyriakis JM, Avruch J (2001) Mammalian mitogen-activated protein kinase signal transduction pathways activated by stress and inflammation. Physio Rev 81: 807-869.

27. St-Denis A, Chano F, Tremblay P, St-Pierre Y, Descoteaux A (1998) Protein kinase $\mathrm{C}$-alpha modulates lipopolysaccharide-induced functions in a murine macrophage cell line. J Biol Chem 273: 32787-32792.

28. Ikeda F, Deribe YL, Skånland SS, Stieglitz B, Grabbe C, et al. (2011) SHARPIN forms a linear ubiquitin ligase complex regulating NF- $\left.\right|^{\circ} \mathrm{B}$ activity and apoptosis. Nature 471: 637-641.

29. Ducut Sigala JL, Bottero V, Young DB, Shevchenko A, Mercurio F, et al. (2004) Activation of transcription factor NF-kappaB requires ELKS, an IkappaB kinase regulatory subunit. Science 304: 1963-1967.

30. Poveda L, Hottiger M, Boos N, Wuertz K (2009) Peroxynitrite induces gene expression in intervertebral disc cells. Spine (Phila Pa 1976) 34: 1127-1133.

31. Nesic O, Lee J, Ye Z, Unabia GC, Rafati D, et al. (2006) Acute and chronic changes in aquaporin 4 expression after spinal cord injury. Neuroscience 143 779-792.

32. Thrane AS, Rappold PM, Fujita T, Torres A, Bekar LK, et al. (2011) Critical role of aquaporin-4 (AQP4) in astrocytic $\mathrm{Ca} 2+$ signaling events elicited by cerebral edema. Proc Natl Acad Sci U S A 108: 846-851.

33. Nito C, Kamada H, Endo H, Narasimhan P, Lee YS, et al. (2012) Involvement of mitogen-activated protein kinase pathways in expression of the water channe protein aquaporin-4 after ischemia in rat cortical astrocytes. J Neurotrauma 29 : 2404-2012.

This article was originally published in a special issue, Brain \& Spinal Cord Injury handled by Editor. Dr. Chen Gaung Yu, University of Kentucky, USA 